\title{
Illness Acceptance as the Measure of the Quality of Life in Moderate Psoriasis
}

\author{
Barbara Jankowiak' \\ Beata Kowalewska' \\ Elżbieta Krajewska- Kułak' \\ Rafał Milewski ${ }^{2}$ \\ Maria Anna Turosz (iD) ${ }^{3}$ \\ 'Department of Integrated Medical Care, \\ Medical University of Bialystok, Bialystok, \\ Poland; ${ }^{2}$ Faculty of Health Sciences \\ Medical University of Bialystok, Bialystok, \\ Poland; ${ }^{3}$ Faculty of Physical Education and \\ Health Jozef Pilsudski University of \\ Physical Education in Warsaw, Faculty in \\ Biala Podlaska, Biala Podlaska, Poland
}

Correspondence: Barbara Jankowiak Department of Integrated Medical Care, Medical University of Bialystok, 7A MC Skłodowskiej Str, Bialystok, I5-096, Poland

Tel +48 857485528

Email barbara.jankowiak@umb.edu.pl

\begin{abstract}
Introduction: Psoriasis is a chronic disease with intermittent flares and remissions. Each individual perceives the disease, its somatic effects, resultant dysfunction and related problems differently. This attitude is primarily determined by one's characterological traits and type of illness. A primary response to the diagnosis can be denial, underestimation, acceptance or overestimation of the disease. The aim of the study was to analyze the level of illness acceptance and its effect on the quality of life in moderate psoriasis depending on sociodemographic and clinical characteristics of the patients.
\end{abstract}

Materials and Methods: The study included 186 patients with plaque psoriasis with Psoriasis Area Severity Index (PASI) scores $\leq 10$. The inclusion criteria of the study were duration of psoriasis $>2$ years, age $\geq 18$ years, and lack of other somatic or mental disorders during three months preceding the study. The study participants completed the Acceptance of Illness Scale (AIS), Dermatology Life Quality Index (DLQI) as well as an original survey containing questions about their sociodemographic characteristics and information about their disease.

Results: Mean AIS score for the study group was 24.3 pts. Patients older than 40 years presented with lower levels of illness acceptance than younger persons $(p=0.0311)$. Also, patients' sex and duration of psoriasis significantly affected the acceptance of the illness, with lower AIS scores found in women $(p=0.0092)$ and persons with a longer history of the disease $(p=0.0362)$. Mean DLQI score for the study group was $13.3 \mathrm{pts}$. A lower level of illness acceptance turned out to exert an unfavorable effect on the quality of life (QOL) in psoriasis $(\mathrm{p}=0.0015 ; \mathrm{R}=-0.33$ ).

Conclusion: In this study, patients with psoriasis presented with a moderate level of the illness acceptance, and a significant correlation was found between this parameter and QOL. Keywords: illness acceptance, psoriasis, psychodermatology, quality of life

\section{Introduction}

Psoriasis is a chronic disease with intermittent flares and remissions. Aside from genetic predisposition and immunological disorders, psychological stress, emotional conflicts, and a tendency to suppress one's emotions are principal factors modifying the disease's course. ${ }^{1-4}$

Given the chronic and recurrent character of psoriasis and multiple triggering factors, treatment of this condition requires a thorough insight into health problems of a given patient, and a physician in charge needs to be experienced in terms of therapy selection. While many anti-psoriatic treatments exist, the therapy should be tailored in each case; the treatment lasts long, and excellent patient-physician cooperation is needed to achieve the desired outcome. ${ }^{5}$

Psoriasis may lead to physical disability (psoriatic arthritis), has an unfavorable effect on the patient's comfort and quality of life, and disrupts normal 
functioning to various degree. Not infrequently, the disease, especially its severe form (erythroderma), ${ }^{2-4}$ is associated with pain and suffering. In other forms of psoriasis, the disease's impact depends on the area of the skin being affected; patients whose skin lesions are visible to others often withdraw from social activities, stay in isolation and may even develop depression. Such persons experience dissatisfaction, guilt, fear and embarrassment, which has a detrimental effect on their quality of life (QOL). Due to the deterioration of QOL, patients with psoriasis may be reluctant to involve in social, family and occupational activities. ${ }^{1,2,6}$ Furthermore, antipsoriatic treatment requires self-discipline and can be burdensome, especially in the case of topical therapies. ${ }^{5}$

Psoriasis is a challenge and requires the patient to face a new reality. Coping with the disease and normal functioning are to a large extent dependent on one's level of illness acceptance. $^{7}$ Each individual perceives the disease, its somatic effects, resultant dysfunction and related problems differently. This attitude is primarily determined by one's characterological traits and type of illness. A primary response to the diagnosis can be denial, underestimation, acceptance or overestimation of the disease. ${ }^{8}$ Some patients accept their illness and self-motivate themselves to participate in the therapeutic process; in such cases, a higher level of illness acceptance is associated with better adjustment to the disease and lesser psychological discomfort. If the disease causes mobilization of one's resources and despite experiencing health problems the patient can pursue his/her objectives and satisfy all vital needs, the level of illness acceptance increases and the QOL is better. ${ }^{9,10}$ However, some patients do not accept their diagnosis and respond with a rebellion, lack of medication compliance, emotional instability and denial. This eventually leads to a low level of illness acceptance and the resultant deterioration of life quality. $^{11,12}$

Acceptance of the illness enables the patients to function normally despite various risks, constraints and problems associated with health loss. Knowing the causes and consequences of their illness, and potential complications thereof, the patients are capable of adequate self-control and can undertake health-oriented behaviors to improve their quality of life and longevity. ${ }^{9,10}$

Therefore, to improve the quality of life in chronically ill persons, healthcare providers should not merely monitor their somatic symptoms, but also assess their current needs, psychosocial, emotional and spiritual wellbeing, and illness acceptance level.
The aim of the study was to analyze the level of illness acceptance and its effect on the quality of life in moderate psoriasis depending on sociodemographic and clinical characteristics of the patients.

\section{Materials and Methods}

The study included patients recruited at private clinic of dermatology and medical cosmetology in Bialystok (Poland). The study group consisted of 186 patients with plaque psoriasis, including 103 of women (55.4\%) and 83 of men $(44.6 \%)$. The study participants were recruited by experienced dermatologist who determined their Psoriasis Area Severity Index (PASI) scores and recorded them in the patients' documentation. The inclusion criteria of the study were: PASI $\leq 10$, duration of psoriasis $>2$ years, age $\geq 18$ years, and lack of other somatic or mental disorders during three months preceding the study.

Two hundred and twenty-five patients were invited to complete a questionnaire. Eighteen patients those who did not express their consent to participate were excluded from the study, and 21 patients did not provide complete answers. Final response and rejection rates were $82.7 \%$ $(n=186)$ and $17.3 \%(n=39)$, respectively.

The study was conducted from June to September 2020. The respondents received questionnaires along with the instructions on how to complete them. The responses were self-reported or filled in by an investigator, either at the clinic or home. Respondents who completed the questionnaire at home received a self-addressed return envelope.

The research conformed with the Good Clinical Practice guidelines, and the procedures followed were in accordance with the Helsinki Declaration.

The study protocol of the was approved by the Local Bioethical Committee at the Medical University of Bialystok (decision no. APK.002.212.2020).

The study patients completed Acceptance of Illness Scale (AIS), Dermatology Life Quality Index (DLQI) and a survey developed by the authors of this study, containing questions about sociodemographic characteristics of the participants (gender, age, place of residence, marital status, education, employment status) and information about their disease (location of psoriatic lesions, time elapsed since the diagnosis of psoriasis).

The level of illness acceptance was measured with the AIS developed by BJ. Felton, TA. Revenson and GA. Hinrichsen and adapted to Polish conditions by Z. Juczyński. ${ }^{13}$ 
Given its psychometric characteristics, AIS is considered an accurate "predictor of health-related quality of life, reflecting one's satisfaction with life and actual health status". ${ }^{13}$

The scale measures the respondent's ability to cope with the illness based on eight statements regarding his/ her actual status of health. Each statement is graded on a 5-point Likert-type scale, from 1 (definitively agree), to 2 (agree), 3 (do not know), 4 (disagree) and 5 (definitively disagree). The level of illness acceptance, being the sum of scores for all eight statements, can range from 8 pts (lack of acceptance) to $40 \mathrm{pts}$ (high level of acceptance).

DLQI contains 10 single-choice questions referring to the quality of life in dermatological disorders. The answer to each question is scored on a scale from 0 to 3 , where 3 corresponds to "very much", 2 to "a lot", 1 to "a little", and 0 to "not at all". The overall DLQI score can range from 0 to 30 . The higher the score, the worse the quality of life in a given patient. ${ }^{14}$

\section{Statistical Analysis}

To obtain a better insight into the problem in question, the levels of illness acceptance were analyzed according to the respondents' sociodemographic characteristics: gender, age, place of residence, marital status, education and occupation, as well as according to clinical characteristics: duration of psoriasis and location of psoriatic lesions. Statistical significance was verified with the Student's $t$-test in the case of comparison between two groups or ANOVA if the number of compared groups was larger than two. The results were considered statistically significant at $\mathrm{p}<0.05$.

An integral part of the study was to analyze the relationship between illness acceptance and quality of life. The analysis was based on Spearman's coefficient of correlation between the two psychometric variables, which is an appropriate statistical measure to investigate non-linear relationships of a monotonous (positive or inverse) type.

The statistical analysis was carried out with STATISTICA 12.5 package.

\section{Results}

The study group consisted exclusively of adult patients $(\mathrm{Me}=36 ; \mathrm{SD}=12,0 ;$ Min./Max. $=18 / 74$ years $)$, with the mean age of 39.4 years.

Mean duration of psoriasis in the study group was 14.8 years $(\mathrm{Me}=14 ; \mathrm{SD}=10,3 ;$ Min. $/$ Max. $=2 / 57$ years $)$.

The study group included $52.7 \%$ of married persons, $23.6 \%$ of singles, $12.4 \%$ of divorcees and $11.3 \%$ of widows/widowers. The proportions of respondents with higher and secondary education were $50 \%$ and $32.8 \%$, respectively, the proportion of participants with primary or vocational education was $18.2 \%$. The vast majority of the study participants were city-dwellers $(75,2 \%)$. The largest occupational group were blue-collar workers (46.8\%), followed by white-collar workers $(38.7 \%)$. The remaining $14.5 \%$ are: retirees and pensioners $(6.5 \%)$, students $(4.8 \%)$, farmers $(2.2 \%)$ and the unemployed (1.1\%).

The illness acceptance scores (AIS) of the study patients were summarized as descriptive statistics. Mean AIS score for the study group was 24.3 pts $(\mathrm{Me}=24$; $\mathrm{SD}=6,1$; Min./Max.=10/40). However, based on the values of the lower and upper quartiles values, most participants scores between 20 and 28 on the AIS scale.

The majority of the respondents (64\%) scored 19-29 pts on the AIS. The proportions of patients presenting with full acceptance of the illness and complete lack of illness acceptance were similar, $19 \%$ and $17 \%$, respectively.

Table I Relationships of Sociodemographic and Clinical Characteristics with AIS Scores

\begin{tabular}{|l|c|c|c|c|}
\hline \multirow{2}{*}{$\begin{array}{l}\text { Sociodemographic and } \\
\text { Clinical Characteristics of } \\
\text { the Patients }\end{array}$} & \multicolumn{3}{|c|}{ AIS } \\
\cline { 2 - 5 } & $\bar{x}$ & SD & $95 \%$ c.i. & P \\
\hline Women & 21.6 & 6.7 & $20.4-25.7$ & $0.0092^{* *}$ \\
Men & 24.9 & 5.2 & $23.2-26.5$ & \\
\hline Countryside & 24.2 & 5.2 & $21.9-26.5$ & 0.9603 \\
Town/City & 24.3 & 6.4 & $22.7-25.9$ & \\
\hline Age <40 & 24.2 & 4.8 & $22.5-25.9$ & $0.0311 *$ \\
Age $\geq 40$ & 22.4 & 6.6 & $21.2-26.6$ & \\
\hline Married & 24.3 & 5.9 & $22.6-26.0$ & 0.9900 \\
Unmarried & 24.3 & 6.5 & $22.2-26.4$ & \\
\hline Higher education & 25.3 & 5.3 & $23.7-26.9$ & 0.1314 \\
Non-higher education & 23.3 & 6.8 & $21.2-25.4$ & \\
\hline Duration of psoriasis <15 & 24.9 & 6.1 & $23.0-26.8$ & $0.0362^{*}$ \\
Duration of psoriasis $\geq 15$ & 21.7 & 4.4 & $21.7-25.6$ & \\
\hline Blue-collar workers & 22.9 & 6.2 & $20.6-25.1$ & 0.1806 \\
White-collar workers & 24.7 & 5.6 & $23.0-26.5$ & \\
\hline Location - exposed body & 22.8 & 5.7 & $21.9-25.8$ & 0.6575 \\
parts (head, hands) & & & & \\
Location - unexposed body & 24.6 & 6.5 & $22.8-26.4$ & \\
parts (torso, legs) & & & & \\
\hline Notes: & & & \\
\hline
\end{tabular}

Notes: *Indicate statistical significance $(\mathrm{p}<0.05)$, **Indicate statistical significance $(\mathrm{p}<0.01) . \bar{x}$ - arithmetic mean, $95 \%$ c.i. $-95 \%$ confidence interval for mean value in a given population. $\mathrm{p}$-values from the Student's $t$-test.

Abbreviation: SD, standard deviation. 
The level of illness acceptance correlated significantly with some sociodemographic characteristics of the study participants (Table 1). Patients older than 40 years presented with lower levels of illness acceptance than younger persons $(\mathrm{p}=0.0311)$. Also, patients' sex and duration of psoriasis significantly affected the acceptance of the illness, with lower AIS scores found in women $(\mathrm{p}=0.0092)$ and persons with a longer history of the disease $(\mathrm{p}=0.0362)$. The illness acceptance scores for patients living in the cities and countryside were similar (24.2 pts vs $24.3 \mathrm{pts}$ ), whereas the mean scores for married persons and singles were the same ( $24.3 \mathrm{pts})$.

DLQI is a scale that measures the negative impact of the disease on QOL; hence, the higher the DLQI score, the more unfavorable the effect of the illness.

Mean DLQI score for the study group was $13.3 \mathrm{pts}$ $(\mathrm{Me}=13 ; \mathrm{SD}=8,1 ; \mathrm{Min} . / \mathrm{Max} .=0-30)$. Based on the values of the lower and upper quartiles values of the DLQI measure ranged from 6.5 to 19 pts.

Table 2 Relationships of Sociodemographic and Clinical Characteristics with DLQI Scores

\begin{tabular}{|c|c|c|c|c|}
\hline \multirow{2}{*}{$\begin{array}{l}\text { Sociodemographic and } \\
\text { Clinical Characteristics of } \\
\text { the Patients }\end{array}$} & \multicolumn{4}{|c|}{ DLQI } \\
\hline & $\bar{x}$ & SD & 95\% c.i. & $p$ \\
\hline Women & 12.7 & 8.2 & $10.0-13.9$ & 0.2054 \\
\hline Men & 14.4 & 7.5 & $11.6-15.8$ & \\
\hline Countryside & 14.7 & 7.8 & $11.4-18.1$ & 0.2883 \\
\hline Town/City & 13.7 & 8.3 & $10.0-14.3$ & \\
\hline Age $<40$ & 13.9 & 8.3 & $11.5-16.3$ & 0.4246 \\
\hline Age $\geq 40$ & 12.5 & 7.9 & $9.9-15.1$ & \\
\hline Married & 12.2 & 7.6 & $10.0-12.4$ & 0.1525 \\
\hline Unmarried & 14.6 & 8.1 & $12.5-17.5$ & \\
\hline Higher education & 11.6 & 7.6 & $9.2-14.2$ & 0.0562 \\
\hline Non-higher education & 14.8 & 8.2 & $12.6-17.5$ & \\
\hline Duration of psoriasis $<15$ & 11.4 & 7.9 & $9.3-14.3$ & 0.0660 \\
\hline Duration of psoriasis $\geq 15$ & 15.8 & 8.2 & $12.4-17.3$ & \\
\hline Blue-collar workers & 14.7 & 8.3 & $12.0-17.3$ & 0.1528 \\
\hline White-collar workers & 12.2 & 7.8 & $9.9-14.4$ & \\
\hline $\begin{array}{l}\text { Location - exposed body parts } \\
\text { (head, hands) }\end{array}$ & 15.8 & 8.0 & $13.0-18.7$ & 0.0583 \\
\hline $\begin{array}{l}\text { Location - unexposed body } \\
\text { parts (torso, legs) }\end{array}$ & 12.3 & 7.6 & $10.0-14.7$ & \\
\hline
\end{tabular}

Notes: $\bar{x}$ - arithmetic mean, $95 \%$ c.i. $-95 \%$ confidence interval for mean value in a given population. $\mathrm{p}$-values from the Student's $t$-test.

Abbreviation: SD, standard deviation.
More than half $(58 \%)$ of the respondents scored no more than 14 pts on the DLQI, which suggests that their quality of life was better than in the remaining $42 \%$ of the patients with DLQI scores higher than 15 pts.

Respondents with primary, vocational or secondary education had worse quality of life than those with higher education (14.8 pts vs $11.6 \mathrm{pts}$ ). Also, persons with longer duration of the disease presented with higher DLQI scores, corresponding to worse quality of life (Table 2).

An integral part of the study was to analyze a link between the level of illness acceptance (AIS score) and the quality of life (DLQI score). The relationship was analyzed based on Spearman's coefficient of correlation between the two psychometric measures.

A lower level of illness acceptance turned out to exert an unfavorable effect on the QOL in psoriasis. While not strong $(R=-0,33)$, the correlation between these two psychometric measures was statistically significant $(\mathrm{p}=$ $0.0015)$ - Figure 1.

The DLQI scores were also stratified according to the level of illness acceptance, and the significance of between-group differences was verified on variance analysis (Table 3). The between-group differences in DLQI scores were shown to be statistically significant $(\mathrm{p}=$ $0.0202)$.

Spearman's coefficients of correlation were also used to analyze the effects of age and duration of psoriasis on the levels of illness acceptance and DLQI scores. The

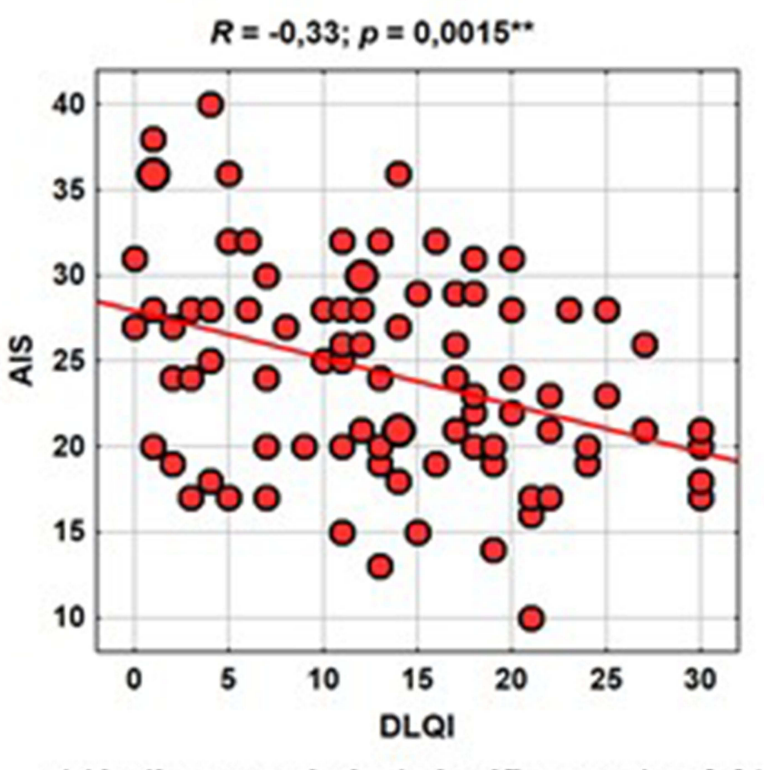

$* *$ indicate statistical significance $(\mathrm{p}<0.01)$

Figure I Correlation between the level of illness acceptance and the quality of life. 
Table 3 Relationship Between the Level of Illness Acceptance and the Quality of Life

\begin{tabular}{|l|c|c|c|c|}
\hline \multirow{2}{*}{$\begin{array}{l}\text { The Level of Illness } \\
\text { Acceptance (Points) }\end{array}$} & \multicolumn{4}{|c|}{ DLQI $(\boldsymbol{p}=\mathbf{0 . 0 2 0 2})$} \\
\cline { 2 - 5 } & $\mathbf{N}$ & $\bar{x}$ & SD & $\mathbf{9 5 \%}$ c.i. \\
\hline $8-18$ & 32 & 15.7 & 8.7 & $10.9-20.6$ \\
$19-29$ & 116 & 14.1 & 8.0 & $11.9-16.2$ \\
$30-40$ & 38 & 8.6 & 6.4 & $5.3-11.9$ \\
\hline
\end{tabular}

Notes: *Indicate statistical significance $(\mathrm{p}<0.05) \cdot \bar{x}$ - arithmetic mean, $95 \%$ c.i.- $95 \%$ confidence interval for mean value in a given population. $\mathrm{p}$-values from on variance test (ANOVA).

Abbreviation: SD, standard deviation.

correlation coefficients between AIS and age and AIS and duration of the disease were $0.03(\mathrm{p}=0.7793)$ and -0.09 $(\mathrm{p}=0.4016)$, respectively, and did not reach the threshold of statistical significance. The correlation coefficients between DLQI and age and DLQI and duration of the disease were $0.00(\mathrm{p}=0.9764)$ and $0.12(\mathrm{p}=0.2723)$, respectively, and also did not reach the threshold of statistical significance.

We analyzed DLQI and AIS scores according to the location of psoriatic lesions (face, arms, legs, trunk); we restricted the analysis to those four body areas as more detailed stratification would produce too small subgroups, and hence, negatively affect the accuracy of the results. Statistical significance was verified with the Student's $t$-test for independent samples. No statistically significant relationships were found between the location of psoriatic lesions, quality of life and illness acceptance.

\section{Discussion}

Adaptation to a chronic illness, including acceptance of the disease, is a complex process modulated by many factors. However, only a few studies analyzed the level of illness acceptance in patients with psoriasis; instead, researchers centered around the quality of life in this disease. We combined these two aspects in our present study, using selected demographic and clinical parameters as exploratory variables, patients with psoriasis.

Aside from somatic morbidities, patients with psoriasis may also present with mental problems, such as anxiety, dissatisfaction, sense of guilt, fear and embarrassment, ${ }^{15-19}$ and psychological disturbances, eg lowered self-esteem, inability to establish social contacts, which may contribute to a substantial deterioration of the QOL. ${ }^{20-24}$ Frequently, a problem is not the disease itself but its perception by the patients, their involvement in the diagnosis and treatment, and finally, acceptance of the illness. Therefore, attempts to improve the quality of life in psoriasis should not be limited merely to the monitoring of somatic symptoms, but also expand onto the assessment of patients' needs, their psychosocial, emotional and spiritual wellbeing, and illness acceptance. $^{25}$

Illness acceptance is a positive attitude towards chronic disease, strengthening the patients and preventing deterioration of their quality of life. Previous studies highlighted the beneficial effects of illness acceptance in terms of psychological and physical comfort. ${ }^{9,26,27}$

In the study conducted by Zielińska-Więczkowska et $\mathrm{al}^{28}$ psoriasis patients presented with a high mean level of illness acceptance (30.37 $7.936 \mathrm{pts})$. High levels of illness acceptance were found in $62.4 \%$ (30-40 pts) of the patients with psoriasis, whereas moderate and low levels were documented in $26.7 \%$ (19-29 pts) and $10.9 \%$ (8-18 pts), respectively.

The mean level of illness acceptance in our present study was lower than the one mentioned above ( $24 \pm 6 \mathrm{pts})$; also, the distribution of AIS scores differed, with $19 \%$ of the patients scoring $30-40$ pts, and $64 \%$ and $17 \%$ having the results in a bracket of 19-29 pts and 8-18 pts, respectively.

The difference in the levels of illness acceptance might be associated with the fact that the majority of patients examined by Zielińska-Więczkowska et $\mathrm{al}^{28}$ were persons aged 51-60 years and older, who constituted $56.4 \%$ of the entire study group. In our present study, the respondents were stratified into different age groups, up to 40 years and older. One could hypothesize that longer duration of psoriasis and older age facilitate coping with the disease and promote its acceptance. According to Harrison et $\mathrm{al}^{29}$ and Mniszewska et $\mathrm{al}^{7}$ the disease with skin manifestations is less likely to negatively affect interpersonal relations of older persons, who have usually achieved stability in their social life and professional career.

However, our findings do not seem to support the hypothesis mentioned above, as these were older respondents who presented with lower levels of illness acceptance.

Similar findings were also reported by Hawro et $\mathrm{al}^{30}$ who showed that the sense of guilt, shame and social rejection in psoriasis increased with age. Older persons were shown to feel rejected, avoided social contacts with their relatives and friends, and presented with lower illness acceptance levels.

However, it needs to be stressed that in the studies conducted by Basińska et $\mathrm{al}^{10}$ the levels of illness acceptance in psoriasis did not correlate significantly with patients' age.

Patients with longer duration of psoriasis were shown to present with lower illness acceptance levels, 
a phenomenon also observed in our present study. According to van Beugen ${ }^{31}$ and Ogarczyk, ${ }^{32}$ patients with a longer history of psoriasis reported more difficulties in social functioning, which corresponded to the lack of illness acceptance and worse quality of life.

In the study conducted by Basińska et $\mathrm{al}^{10}$ patients with psoriasis presented with higher levels of illness acceptance (27.46 pts) than in our present study (24.3 pts). The authors did not find a significant difference in the illness acceptance levels of female (26.49 pts) and male patients (28.41 pts). This observation is consistent with the results of some previous studies, conducted by Sampognab et $\mathrm{al}^{33}$ Mniszewska et $\mathrm{al}^{34}$ and other authors, which also did not demonstrate a significant effect of patients' sex on QOL. ${ }^{35,36}$ In the study conducted by Zielińska Więczkowska et $\mathrm{al}^{28}$ female patients had lower AIS scores than male psoriatics (54.2 pts vs.73.8 pts), but the difference was not statistically significant. Also, in our present study women scored lower than men in terms of illness acceptance (24.9 pts vs $23.6 \mathrm{pts}$ ).

According to Hawro et $\mathrm{al}^{30}$ female psoriatics also presented with lower quality of life scores. Psoriasis makes female patients feel embarrassed, frustrated and irritated. Due to the altered appearance of their skin, women with psoriasis found themselves unattractive and avoid contacts with others. Similar results were also reported by Zachariae et $\mathrm{al}^{37}$ and Kowalewska et al. ${ }^{27}$ However, according to other authors, these were male patients with psoriasis who presented with lower QOL scores than female patients. $^{7,26}$

To summarize, the results of previous studies analyzing the effects of age and sex on illness acceptance and quality of life in psoriasis are inconclusive. ${ }^{20,37,38}$

Location of psoriatic lesions is known to influence both the illness acceptance and QOL. ${ }^{30,31,39}$ Krueger et al ${ }^{2}$ demonstrated that the lesions on exposed body parts attracted more attention from the others and had a negative effect on the social relationships of patients with psoriasis. To cover their skin lesions, patients with psoriasis not infrequently wear uncomfortable clothing. Hiding psoriatic lesions from others is considered an unpleasant duty and was shown to have a detrimental effect on QOL, especially in female patients. ${ }^{1,2}$ According to Hrehorów et a ${ }^{40}$ psoriasis exerts an unfavorable effect on the social contacts of the patients. Patients with visible skin lesions experience a growing sense of shame and embarrassment since they believe that other healthy persons avoid them not to be infected.
Our present study showed that visible psoriatic lesions were a factor contributing to the lack of illness acceptance.

This problem was previously highlighted by Orzechowska et $\mathrm{al}^{41}$ according to whom psoriatic lesions are a primary factor resulting in the stigmatization of the patients and resultant disruption of their social functioning. The patients who do not approve their disease-altered appearance may share a common misbelief that their image is also not accepted by others; thus, such patients not infrequently may self-stigmatize themselves. According to Russo et al, up to $89 \%$ of patients with psoriasis experienced shame and embarrassment because of their skin lesions. ${ }^{42}$

In Devrimci-Ozguven's et $a^{43}$ Hrehorów et al ${ }^{40}$ opinion, psoriasis may have a detrimental effect on a patient's mood, and some patients with psoriasis may even have suicidal thoughts. Such persons cannot accept their selfimage and are exhausted with long-term treatment of skin lesions. Another risk factor for the suicidal ideation in patients with psoriasis is social rejection resulting from the lack of acceptance from others. ${ }^{40,42-44}$

Education and occupation do not seem to influence the level of illness acceptance in psoriasis, ${ }^{28}$ which has also been confirmed in our present study. Perhaps, this phenomenon resulted from a relative stability of work environment.

In our study, married persons and singles have the same mean Scale AIS scores (24.3 pts), and hence, marital status was not confirmed as a significant determinant of the illness acceptance. However, in previous studies, conducted by $\mathrm{Lu}$ et $\mathrm{al}^{36}$ van Beugen et $\mathrm{al}^{31}$ and Ginsburg et al ${ }^{45}$ singles were shown to be more prone to stigmatization, which was also reflected by their worse quality of life.

Published data show unequivocally that psoriasis exerts a detrimental effect on the QOL. The disease constitutes a considerable burden for the vast majority of the patients, which is reflected by unfavorable changes in their quality of life. In turn, acceptance of the illness was associated with a better quality of life in psoriasis, ${ }^{46}$ the relationship also observed in our present study $(\mathrm{p}=0.0015)$.

The persistence of psoriatic skin manifestations instead of treatments could deeply influence the patient attitude toward the disease. ${ }^{5,25}$ According to Verhoeven et $\mathrm{al}^{47}$ deterioration of the quality of life in psoriasis is associated with somatic manifestations of the disease. As emphasized by Ograczyk et $\mathrm{al}^{32}$ persistent itchiness and flares of the disease contribute to the escalation of anxiety and 
psychological discomfort. According to Hrehorów et $\mathrm{al}^{46}$ itchiness is the main obstacle in illness acceptance. Persons with clinical manifestations of psoriasis were shown to have lower self-esteem and lower levels of satisfaction with life. Patients with psoriasis are well aware that their illness is chronic and incurable, with symptomatic treatment and maintenance of the remission being the only viable therapeutic options. Patient's perspective is important not only in terms of symptoms but also on the well-being impact. ${ }^{25}$

According to literature, the higher the level of illness acceptance, the better the adjustment to the disease and the lesser the negative emotions experienced by patients with psoriasis. $^{26,27,40,42}$ Thus, the patients who give less meaning to their condition are more likely to accept the illness and to choose more appropriate coping strategies to avoid unfavorable negative psychosocial consequences of psoriasis.

\section{Conclusions}

In this study, patients with moderate psoriasis presented with a moderate level of the illness acceptance, and a significant correlation was found between this parameter and QOL. This implies that both illness acceptance and subjectively assessed QOL are accurate psychometric measures that should be considered during anti-psoriatic treatment planning.

\section{Data Sharing Statement}

The datasets generated during and/or analyzed during the current study are available from the corresponding author on reasonable request.

\section{Ethics}

Compliance with ethics guidelines: the protocol of the study was approved by the Local Bioethics Committee at the Medical University of Bialystok. Informed consent was obtained from all individual participants included in the study.

\section{Acknowledgments}

The authors would like to thank the patients who participated in the survey.

\section{Author Contributions}

All authors contributed to data analysis, drafting or revising the article, have agreed on the journal to which the article will be submitted, gave final approval of the version to be published, and agree to be accountable for all aspects of the work.
Barbara Jankowiak was a major contributor in writing the manuscript and supervised this study. Was responsible for patient recruitment, data collection, data analysis, and drafting the manuscript.

Beata Kowalewska was a major contributor in writing the manuscript, was involved in the development of the idea, data analysis, and drafting the manuscript.

Elżbieta Krajewska-Kułak was involved in the development of the idea and revised the manuscript critically for important intellectual content.

Rafał Milewski was involved in the development of the idea and revised the manuscript critically for important intellectual content.

Maria Anna Turosz was involved in the development of the idea and revised the manuscript critically for important intellectual content.

\section{Funding}

This study and the Rapid Service Fee were funded by Medical University of Bialystok, Poland. All authors had full access to all of the data in this study and take complete responsibility for the integrity of the data and accuracy of the data analysis. Neither honoraria nor other forms of payments were made for authorship.

\section{Disclosure}

The authors report no conflicts of interest for this work.

\section{References}

1. Ferreira BI, Abreu JL, Reis JP, et al. Psoriasis and associated psychiatric disorders a systematic review on etiopathogenesis and clinical correlation. J Clinic Aesthet Dermatol. 2016;9(6):36-43.

2. Krueger G, Koo J, Lebwohl M, et al. The impact of psoriasis on quality of life: results of a 1998 national psoriasis foundation patient- membership survey. Arch Dermatol. 2001;137(3):280-284.

3. Langley RGB, Krueger GG, Griffiths CEM. Psoriasis: epidemiology, clinical features, and quality of life. Ann Rheum Dis. 2005;64(Supp12): ii18-ii23. doi:10.1136/ard.2004.033217

4. Christophers E. Psoriasis -epidemiology and clinical spectrum. Clin Exp Dermatol. 2001;26(4):314-320. doi:10.1046/j.1365-2230.2001.00832.x

5. Scala E, Megna M, Amerio P, et al. Patients' demographic and socioeconomic characteristics influence the therapeutic decision-making process in psoriasis. PLoS One. 2020;15(8):e0237267. doi:10.1371/journal. pone. 0237267

6. Gelfand JM, Feldman SR, Stern RS, et al. Determinants of quality of life patients with psoriasis: a study from the U.S. population. $J \mathrm{Am}$ Acad Dermatol. 2004;51(5):704-708. doi:10.1016/j.jaad.2004.04.014

7. Miniszewska J, Juczyński Z, Ograczyk A, et al. Health-related quality of life in psoriasis: important role of personal resources. Acta Derm Venereol. 2013;93(5):551-556. doi:10.2340/00015555-1530

8. Bowling A, Farquhar M, Browne P. Life satisfaction and associations with social network and support variables in three samples of elderly people. Int J Geriatr Psychiatr. 1991;6(8):549-566. doi:10.1002/gps.930060803 
9. Zalewska A, Miniszewska J, Chodkiewicz J, et al. Acceptance of chronic illness in psoriasis vulgaris patients. $J$ Eur Acad Dermat Venereol. 2007;21(2):235-242. doi:10.1111/j.1468-3083.2006.01912. $\mathrm{x}$

10. Basińska MA, Woźniewicz A. Emotional intelligence in psoriasis patients as a determinant of acceptance of illness. Rev Dermat. 2012;99(3):202-209.

11. Ginsburg IH. Psychological and psychophysiological aspects of psoriasis. Derm Clin. 1995;13(4):793-804. doi:10.1016/S07338635(18)30043-3

12. Zachariae R, Oster H, Bjerring P, et al. Effects of psychologic intervention on psoriasis: a preliminary report. $J$ Am Acad Dermatol. 1996;34(6):1008-1015. doi:10.1016/S0190-9622(96) 90280-7

13. Juczyński Z. Narzędzia Pomiaru w Promocji I Psychologii Zdrowia [Measurement Tools in Health Promotion and Psychology]. Warszawa: Pracownia Testów Psychologicznych Polskiego Towarzystwa Psychologicznego; 2001:168-172. Polish.

14. Szepietowski J, Salomon J, Finlay AY, et al. Dermatology Life Quality Index (DLQI): polish version. Dermatol Klin. 2004;6:63-70.

15. Gupta MA. Psychosocial aspects of common skin disease. Can Fam Physician. 2002;48:712-716.

16. Gupta MA, Gupta AK. Psychiatric and psychological comorbidity in patients with dermatologic disorders: epidemiology and management. Am J Clin Dermatol. 2003;4(12):833-842. doi:10.2165/00128071200304120-00003

17. Picardi A, Abeni D, Melchi CF, et al. Psychiatric morbidity in dermatological outpatients: an issue to be recognized. Br J Dermatol. 2000;143 (5):983-991. doi:10.1046/j.1365-2133.2000.03831.x

18. Picardi A, Amerio P, Baliva G, et al. Recognition of depressive and anxiety disorders in dermatological outpatients. Acta Derm Venereol. 2004;84(3):213-217. doi:10.1080/00015550410025264

19. Gieler U, Kupfer J, Niemeier V, et al. Psyche and skin: what's new? J Eur Acad Dermatol Venereol. 2003;17(2):128-130. doi:10.1046/ j.1468-3083.2003.00618.x

20. de Korte J, Sprangers MAG, Mombers FMC, et al. Quality of life in patients with psoriasis: a systematic literature review. J Investig Dermatol Symp Proc. 2004;9(2):140-147. doi:10.1046/j.10870024.2003.09110.x

21. Finlay A. Psoriasis from the patient's point of view. Arch Dermatol. 2001;137(3):352-353.

22. Heydendael VM, de Borgie CA, Spuls PI, et al. The burden of psoriasis is not determined by disease severity only. J Investig Dermatol Symp Proc. 2004;9(2):131-135. doi:10.1111/j.10870024.2004.09115.x

23. Vardy D, Besser A, Amir M, et al. Experiences of stigmatization play a role in mediating the impact of disease severity on quality of life in psoriasis patients. Br J Dermatol. 2002;147(4):736-742. doi:10.1046/ j.1365-2133.2002.04899.x

24. Gupta MA, Gupta AK. A practical approach to the assessment of psychosocial and psychiatric comorbidity in the dermatology patient. Clin Dermatol. 2013;31(1):57-61. doi:10.1016/j.clindermatol.2011.11.007

25. Patruno C, Ayala F, Megna M, et al. Patient-physician relationship in patients with psoriasis. Indian J Dermatol Venereol Leprol. 2012;78 (2):228. doi:10.4103/0378-6323.93657

26. Kostyła M, Tabała K, Kocur J. Illness acceptance degree versus intensity of psychopathological symptoms in patients with psoriasis. Postepy Dermatol Alergol. 2013;30(3):134-139. doi:10.5114/ pdia.2013.35613

27. Kowalewska B, Cybulski M, Jankowiak B, et al. Acceptance of illness, satisfaction with life, sense of stigmatization, and quality of life among people with psoriasis: a cross-sectional study. Dermatol Ther (Heidelb). 2020;10(3):413-430. doi:10.1007/s13555-02000368-w
28. Zielińska-Więczkowska H, Pietrzak N. Akceptacja choroby i jej związek z jakością życia pacjentów z łuszczycą [Acceptance of illness and its correlation with the quality of life in patients with psoriasis]. Med Rodz. 2018;21(1):3-9. Polish.

29. Harrison T, Stuifbergen A, Adachi E, et al. Marriage, impairment and acceptance in persons with multiple sclerosis. West J Nurs Res. 2004;26(3):266-285. doi:10.1177/0193945903260188

30. Hawro T, Janusz I, Miniszewska J, et al. Jakość życia i stygmatyzacja a nasilenie zmian skórnych i świądu u osób chorych na łuszczycę [Quality of life and stigmatization and the severity of skin lesions and itching in patients with psoriasis]. In: Rzepa T, Szepietowski J, Żaba R, editors. Psychologiczne I Medyczne Aspekty Chorób Skóry [Psychological and medical aspects of skin diseases]. Cornetis: Wrocław; 2011:42-51. Polish.

31. van Beugen S, van Middendorp H, Ferwerda M, et al. Predictors of perceived stigmatization in patients with psoriasis. $\mathrm{Br} J$ Dermatol. 2017;176(3):687-694. doi:10.1111/bjd.14875

32. Ograczyk A, Miniszewska J, Kępska A, et al. Itch, disease coping strategies and quality of life in psoriasis patients. Postep Derm Alergol. 2014;31(5):299-304.

33. Sampogna F, Sera F, Mazzotti E, et al. Performance of the self-administered psoriasis area and severity index in evaluating clinical and sociodemographic subgroups of patients with psoriasis. Arch Dermatol. 2003;139(3):353-358. doi:10.1001/archderm.139.3.353

34. Miniszewska J, Adamska M. Przekonania na temat zdrowia i choroby a akceptacja ograniczeń wynikających z przewlekłej choroby somatycznej na przykładzie osób z łuszczycą. Psychiatr Psychol Klin. 2014;14(3):202-212. doi:10.15557/PiPK.2014.0029

35. Zięciak T, Rzepa T, Król J, et al. Feelings of stigmatization and depressive symptoms in psoriasis patients. Psychiatr Pol. 2017;51 (6):1153-1163. doi:10.12740/PP/68848

36. Lu Y, Duller P, van der Valk PGM, et al. Helplessness as predictor of perceived stigmatization in patients with psoriasis and atopic dermatitis. Dermatol Psychosomatik. 2003;4(3):146-150. doi:10.1159/000073991

37. Zachariae R, Zachariae H, Ibsen HHW, et al. Psychological symptoms and quality of life of dermatology outpatients and hospitalized dermatology patients. Acta Derm Venereol. 2004;84(3):205-212. doi:10.1080/00015550410023284

38. Fortune DG, Main CJ, O'Sullivan TM, et al. Quality of life in patients with psoriasis: the contribution of clinical variables and psoriasis-specific stress. $\mathrm{Br} J$ Dermatol. 1997;137(5):755-760. doi:10.1111/j.1365-2133.1997.tb01113.x

39. Orion E, Wolf R. Psychologic consequences of facial dermatoses. Clin Dermatol. 2014;32(6):767-771. doi:10.1016/j.clindermatol.20 14.02.016

40. Hrehorów E, Salomon E, Matusiak $\mathrm{E}$, et al. Patients with psoriasis feel stigmatized. Acta Derm Venereol. 2012;92(1):67-72. doi:10.2340/00015555-1193

41. Orzechowska A, Talarowska M, Wysokiński A, et al. Wybrane czynniki psychologiczne w łuszczycy i trądziku różowatym. Dermatol Klin. 2009;11(1):17-20.

42. Russo PAJ, Ilchef R, Cooper AJ. Psychiatric morbidity in psoriasis: a review. Australas J Dermatol. 2004;45(30):155-161. doi:10.1111/ j.1440-0960.2004.00078.x

43. Devrimci-Ozguven H, Kundakci TN, Kumbasar H, et al. The depression, anxiety, life satisfaction and affective expression levels in psoriasis patients. J Eur Acad Dermatol Venereol. 2000;14 (4):267-271. doi:10.1046/j.1468-3083.2000.00085.x

44. Karia SB, De Sousa A, Shah N, et al. Psychiatric morbidity and quality of life in skin diseases: a comparison of alopecia areata and psoriasis. Ind Psychiatry J. 2015;24(2):125-128. doi:10.4103/09726748.181724

45. Ginsburg IH, Link BG. Feelings of stigmatization in patients with psoriasis. J Am Acad Dermatol. 1989;20(1):53-63. doi:10.1016/ S0190-9622(89)70007-4 
46. Hrehorów E, Reich A, Szepietowski J. Jakość życia chorych na łuszczycę: zależność od świądu, stresu i objawów depresyjnych [Quality of life in patients with psoriasis: dependence on pruritus, stress and depressive symptoms]. Dermatol Klin. 2007;9(1):19-23. Polish.
47. Verhoeven EWM, Kraaimaat FW, van de Kerkhof PCM, et al. Prevalence of physical symptoms of itch, pain and fatigue in patients with skin diseases in general practice. Br J Dermatol. 2007;156 (6):1346-1349. doi:10.1111/j.1365-2133.2007.07916.x

\section{Publish your work in this journal}

Clinical, Cosmetic and Investigational Dermatology is an international, peer-reviewed, open access, online journal that focuses on the latest clinical and experimental research in all aspects of skin disease and cosmetic interventions. This journal is indexed on CAS.
The manuscript management system is completely online and includes a very quick and fair peer-review system, which is all easy to use. Visit http://www.dovepress.com/testimonials.php to read real quotes from published authors. 